\title{
Disability grading in leprosy. Suggested modifications to the WHO disability grading form
}

\author{
J W BRANDSMA, N de JONG \& T TJEPKEMA \\ Physiotherapy Department, All Africa Leprosy and Rehabilitation \\ Training Center (ALERT), PO Box 165, Addis Ababa, Ethiopia.
}

Accepted for publication 4 March 1986

\begin{abstract}
Summary Disability prevention should be the primary objective of a leprosy control programme. Although the initial purpose of the WHO recommended disability grading system is to provide an index of the presence of disabilities, regularly performed disability assessment will also be very useful to a leprosy control programme to assist in planning measures to prevent disabilities and to evaluate the effectiveness of a disability prevention programme. Modifications of the WHO disability grading form are proposed.
\end{abstract}

\section{Introduction}

Disabilities and deformities in leprosy patients are not an inevitable result of the disease except for a few deformities such as collapse of the nose or loss of eyebrows in untreated, advanced lepromatous leprosy. The majority of disabilities and deformities are attributable to peripheral nerve damage. Early diagnosis, regular and adequate treatment and early recognition of decreasing nerve function are of utmost importance to prevent and reverse nerve damage. In 1970 The World Health Organization (WHO) recommended a new disability grading system for leprosy patients, Table 1. ${ }^{1}$ The purpose of grading of disabilities is to have an index of the presence and severity of disabilities of a patient or a patient population that would be a useful tool in evaluating the programme and assessing the need for special preventive measures. Grading is also useful for comparing data from different countries or different control areas in the same country. It was realized that the grading system should be simple and practical to use for auxiliary health workers.

In 1981 a disability survey was started in the leprosy control area of the All Africa Leprosy and Rehabilitation Training Centre (ALERT). The main purpose for this disability survey was to determine the number of patients in need of protective footwear. Following the survey we were able to produce a realistic 


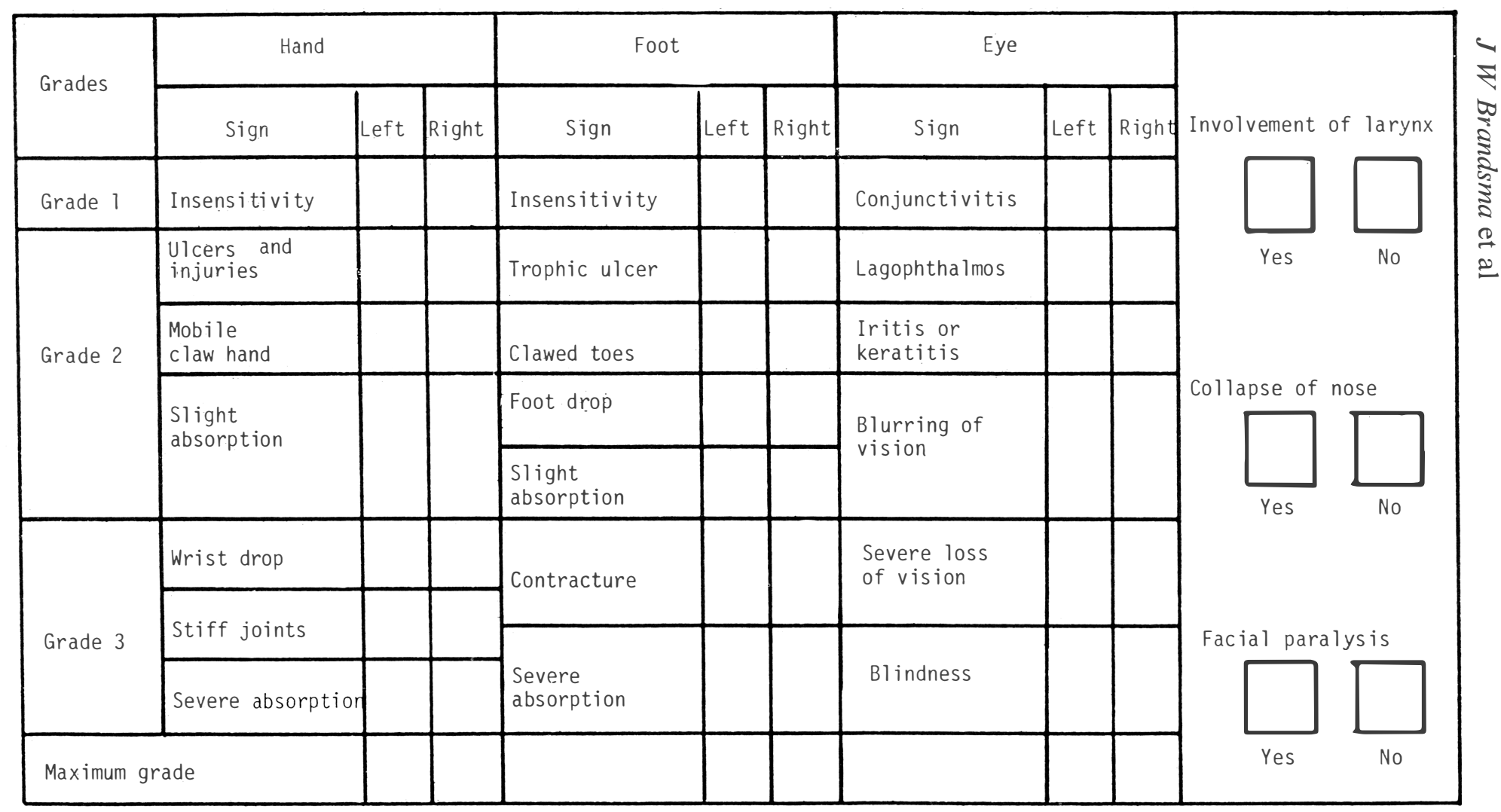

Table 1. WHO form for recording disabilities from leprosy 


\begin{tabular}{|c|c|c|c|c|c|c|c|c|c|}
\hline \multirow[t]{2}{*}{ Grades } & \multicolumn{3}{|l|}{ Eye } & \multicolumn{3}{|l|}{ Hand } & \multicolumn{3}{|l|}{ Foot } \\
\hline & Sign & Right & Left & Sign & Right & Left & Sign & Right & Left \\
\hline Grade 1 & \begin{tabular}{|l|} 
Conjunctivitis \\
Loss of sensation
\end{tabular} & & & $\begin{array}{l}\text { Loss of protec- } \\
\text { tive sensation }\end{array}$ & & & $\begin{array}{l}\text { Loss of protec- } \\
\text { tive sensation }\end{array}$ & & \\
\hline \multirow{4}{*}{ Grade 2} & Lagophthalmos & & & Mobile claw hand & & & Foot drop & & \\
\hline & & & & & & & Clawed toes & & \\
\hline & Iritis-Keratitis & & & $\begin{array}{l}\text { Ulcers-injuries } \\
\text { Cracks }\end{array}$ & & & $\begin{array}{l}\text { Ulcers-injuries } \\
\text { Cracks }\end{array}$ & & \\
\hline & $\begin{array}{l}\text { Slight loss of } \\
\text { vision }\end{array}$ & & & Slight absorption & & & Slight absorption & & \\
\hline \multirow{3}{*}{ Grade 3} & $\begin{array}{l}\text { Total facial } \\
\text { palsy }\end{array}$ & & & Wrist drop & & & & & \\
\hline & $\begin{array}{l}\text { Severe lass of } \\
\text { vision }\end{array}$ & & & Severe absorption & & & Severe absorption & & \\
\hline & Blindness & & & Stiff joints & & & Stiff ankle joint & & \\
\hline \multicolumn{2}{|c|}{ Maximum Grade } & & & & & & & & \\
\hline \multicolumn{4}{|c|}{ Involvement of larynx } & & & & & & \\
\hline \multicolumn{2}{|c|}{ Collapse of nose } & & & & & & & & \\
\hline \multirow{2}{*}{$\begin{array}{l}\text { Muscle } \\
\text { Testing }\end{array}$} & & & & Small Finger Abd. & & & \multirow{2}{*}{ Foot up } & & \\
\hline & tye closure & & & Thumb Abduction & & & & & \\
\hline
\end{tabular}

Key for muscle testing ...... S $=$ Strong $\quad W=$ Weak $\quad P=$ Paralyzed

Table 2. Modified WHO disability grading form

estimation for the budget that would be needed to provide patients with insensitive feet with protective footwear.

Special classes were conducted for the leprosy supervisors and health workers to instruct them on the disability grading and the use of the form. During the first few months we received many comments and suggestions from the leprosy field staff and we decided we should modify the WHO form only when the changes would help the field workers to understand the disabilities better and when it would help them to grade the disabilities more accurately. After 6 months we introduced a new form (Table 2) to facilitate disability recording. The changes in layout, terminology and definitions are summarized in Table 3. 


\begin{tabular}{|c|c|c|}
\hline & W.H.O. Form & Modifications \\
\hline Lay-out & $\begin{array}{l}\text { Similar disabilities of the eyes, } \\
\text { hands and feet, are arranged on a } \\
\text { different level on the form } \\
\text { Order of examination: } \\
\text { Hands--Feet--Eyes } \\
\text { Total facial paralysis is mentioned, } \\
\text { but not given a disability grade. } \\
\text { Left Right }\end{array}$ & $\begin{array}{l}\text { Similar disabilities of the eyes, } \\
\text { hands, and feet are, when appropriate, } \\
\text { arranged on the same level on the form } \\
\text { Order of examination: } \\
\text { Eyes--Hands--Feet } \\
\text { Total facial paralysis is given a } \\
\text { grade } 3 \text { disability } \\
\text { Right Left }\end{array}$ \\
\hline Terminology & $\begin{array}{l}\text { Insensitivity } \\
\text { Blurring of vision } \\
\text { Trophic ulcer of the foot } \\
\text { Contracture of the foot }\end{array}$ & $\begin{array}{l}\text { Loss of nrotective sensation } \\
\text { Slight loss of vision } \\
\text { Injury, ulcer or deep open crack } \\
\text { of the foot } \\
\text { Contracture of the ankle joint }\end{array}$ \\
\hline Definitions & $\begin{array}{l}\text { Loss of vision is defined bv the } \\
\text { patient's ability to see the aap in } \\
\text { the } C \\
\text { ilobility of the hand is defined as the } \\
\text { lack of passive rance of movement } \\
\text { in degrees } \\
\text { Absorntion of the hands and feet, is } \\
\text { defined by the amount of tip } \\
\text { absorption of the finaers and the } \\
\text { amount of loss of sole area for the } \\
\text { feet }\end{array}$ & $\begin{array}{l}\text { Loss of vision is defined by the } \\
\text { patient's inability to count fingers } \\
\text { from a certain distance } \\
\text { Mobility of the hand is defined as the } \\
\text { ability to passively extend the } \\
\text { proximal interphlangeal joints } \\
\text { Absorption of the hands and feet, is } \\
\text { defined by how much of the oriainal } \\
\text { length of the hand or foot is left } \\
\text { (including internal absorption) }\end{array}$ \\
\hline
\end{tabular}

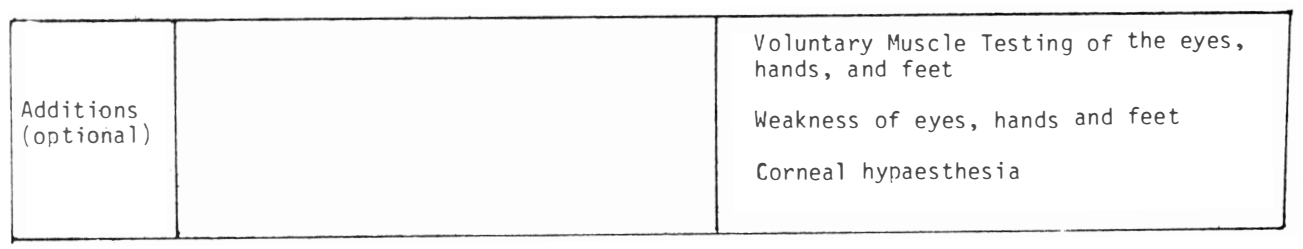

Table 3.

Additional comments will be given here only where the form, terminology and definitions differ significantly from the WHO form.

\section{Layout of forms}

There is a danger of introducing infection to the eye after examination of hands and feet. It seems, therefore, proper to examine eyes prior to the hands and feet. 
Left and right have been reversed in the modified form. With the patient usually seated across from the examiner, our health workers found it much easier to record the disabilities if the side of the patient being tested corresponded to the form.

\section{Terminology and definitions}

\section{LOSS OF PROTECTIVE SENSATION}

We taught our health workers to test for sensation of the eye only when the patient was unable to close his eye or when there was no regular blink. We feel that protective sensation is present when the patient blinks regularly. It is common to test for conjunctival sensation by testing the inner lining of the lower lid. We found that many normal controls did not react to such stimulus and claimed that they did not feel it. We now recommend that the limbus of the cornea is gently touched with a piece of tissue paper or a wisp of clean cottonwool. We consider corneal hypaesthesia a severe disability and suggest therefore that it is included in a disability assessment.

It is advisable that a surgical nylon or fishing nylon be used for hands and feet to determine whether there is protective sensation. When the nylon buckles on a sensitive laboratory scale it should balance the scale at approximately $10 \mathrm{~g}$ or less. Though it can be safely stated that a patient has loss of protective sensation when he is not able to feel a ball-point pen that gently depresses the skin, it cannot be concluded that the patient has protective sensation when he is able to feel it. This test is too crude to determine the level of protective sensation. Many patients with loss of protective sensation do not have completely insensitive hands or feet and will be able to appreciate sensory stimuli of sufficient magnitude. For sensory testing we suggest the testing sites as in Figure 1.

\section{BLURRING OF VISION}

The auxiliary health worker did not always understand the term "blurring of vision'. Also the recommended C-chart was very often not available. To remedy these two problems we redefined blurring of vision as slight loss of vision. This is when the patient is unable to count fingers at a distance of 5 meters. In severe loss of vision the patient is unable to count fingers held closely in front of his face.

\section{TROPHIC ULCER}

The adjective trophic was very often not understood and misinterpreted. Just ulcer would be much better. We have included injury and deep open cracks as grade 2 disability. In the insensitive hand and foot they are often signs of misuse, disuse and neglect in care. 

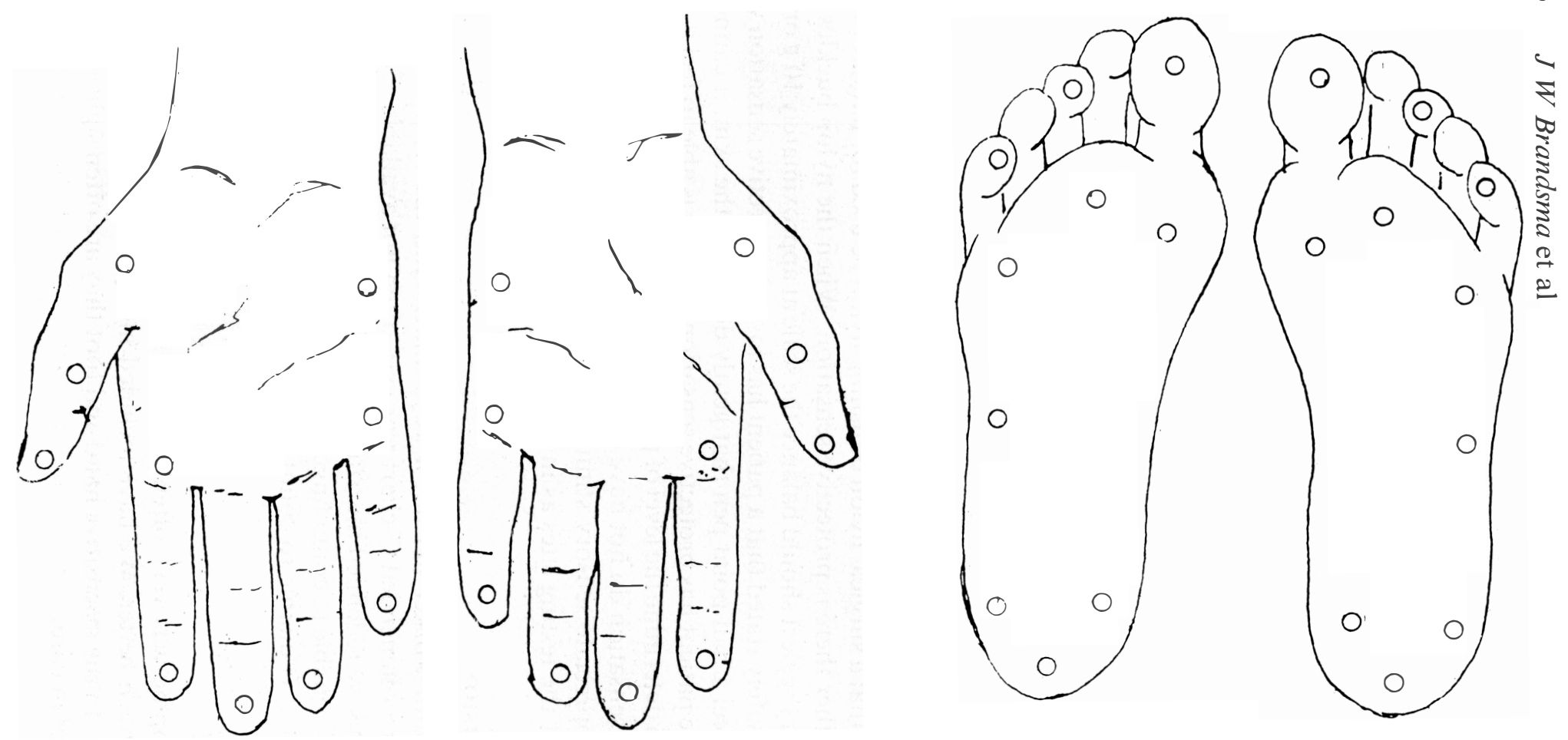

Figure 1. Suggested test sites for sensory testing. There are 10 selected sites each for the hand and the foot. For detailed disability recording and nerve function evaluation the examiner could record the number of stimuli felt ( $\mathrm{v}$, felt; $\mathrm{x}$, not felt). Alternately the examiner could write in the number of the bristle felt at the testing site if a set of graded bristles is being used. 


\section{ABSORPTION}

Hands. If only the distal phalanx of one or more fingers is missing, a hand can still be classified as grade 2 . If there is also absorption of the middle phalanx, the hand should be given a grade 3 disability. When the finger has lost more than $\frac{1}{3}$ of its original length, as in the case of internal absorption, the hand should also be graded 3.

Feet. If one or more toes are missing the foot should be given a grade 2 disability. If there is more absorption than just the toes, the foot should be graded as 3. In the case of internal absorption, the foot should be given a grade 3 when the foot has lost more than $\frac{1}{5}$ of its original length.

\section{STIFF JOINTS}

Fingers. The examiner tries to straighten the interphalangeal joints of the fingers. When he can straighten the fingers completely or almost completely the fingers are mobile. When the examiner cannot straighten the fingers, they are stiff.

Foot. With contracture of the foot, contracture of the ankle and subtalar joint is implied and therefore the latter is the better wording. The examiner tries to dorsiflex, pronate and supinate the ankle and subtalar joint. When these movements are limited, the ankle joint is stiff and the foot has a grade 3 disability.

\section{Discussion}

Disability grading of leprosy patients will be very useful only when it is done on a regular basis and the collected data is analysed. The leprosy control officer will be able to determine if fewer patients report with disabilities than when a programme was first started or when disabilities were first being assessed. Also he will be able to determine if patients do develop disabilities after start of treatment. It will be helpful, also, to assess the need for protective footwear and corrective surgery. It is a good epidemiological parameter and it will reflect the level of care and services of a programme over an extended period of time..$^{2-7}$ We still believe that grading should be simple for the health worker to use. They very often do not have sufficient training and education to do a more detailed grading of disabilities. Hasan ${ }^{8}$ and Kulkarni ${ }^{9}$ in India have modified the WHO grading by increasing the number of grades allowing for more detailed and accurate recording of the various disabilities. With well-trained leprosy workers, as often is the case in India, we feel that a more detailed grading can be done as long as the grades can be reduced again to the recommended three by WHO for comparison and evaluation of data on an international level. Our form has blank boxes that can be used to comment on other disabilities not mentioned or give more detail on hand and foot disabilities. For better trained and more experienced leprosy 
workers it is suggested that the boxes to record loss of protective sensation and clawing be divided so that ulnar and median nerves can be graded separately. For ulcers and injuries the localization could be written down in the box, e.g., U-MH1, which would be an ulcer on the first metatarsal head.

It should always be noted when a disability is not due to leprosy but to other diseases or accidents. In this regard, it should be mentioned that conjunctivitis is very common where there is a high incidence of trachoma and that therefore grade 1 for the eye can easily be an over grading. We would like to emphasize here that we consider loss of protective sensation a severe disability from which other disabilities and deformities may result. The dividing into three grades-1, mild; 2 , moderate; and 3, severe-is only a relative grading system and does not necessarily indicate the degree of functional disability in an individual patient.

The patients with grade 1 disability need the maximum attention to prevent disabilities and deformities due to loss of protective sensation. Health education for these patients is extremely important. Grade 2 patients may benefit from therapeutic action such as surgical correction of paralytic deformities and ulcer treatment. Preventive measures such as protective footwear and exercises are also important at this stage to prevent further disabilities. The patients with grade 3 disability have often been detected too late or may have become disabled before effective treatment was available. These patients also may still, very often, benefit from our services.

It is important to realize that patients may develop more disabilities without a change in the disability grading. For example, when a patient has slight absorption of the fingers, the hand has a grade 2 disability. If the patient now also develops complete intrinsic paralysis of the hand, the hand will still be given a grade 2 disability. The disability grade therefore does not adequately evaluate the condition of the leprosy patient. Disability grading is not a substitute for regular muscle testing and detailed sensory testing to detect early nerve function loss or to follow patients with acute nerve involvement.

The disability grading should preferably be done when the patient is diagnosed, yearly thereafter and when the patient is released from treatment.

On the other hand, nerve function should be assessed when the patient is first diagnosed to serve as a baseline for future reference and thereafter whenever the patient complains of nerve discomfort, numbness, pain or muscle weakness. In the absence of nerve sympioms it is advisable that a basic nerve function assessment be performed at 6-monthly intervals to detect early nerve function loss. Nerve function assessments should be repeated every other week or even weekly when a patient is being treated for recent nerve function loss to monitor change in nerve function status. Nerve function assessment should also be done when the patient is discharged from treatment and should be repeated whenever the patient is reviewed after having been released from drug treatment.

We consider weakness a disability and suggest that muscle testing be included, since weakness very often is detected only by muscle testing. We strongly advise 
that no patient be started on treatment or released from treatment until having both a nerve function assessment and disability grading. Ideally, upon follow-up, the nerve function and the disability index should be the same or better than when the patient was first seen. Downgrading of the disability index would reflect lack of attention and care or inadequate medical treatment.

For more information about indications and techniques on voluntary muscle testing and sensory testing we refer to the references. ${ }^{10-15}$

\section{References}

1 World Health Organization. A guide to leprosy control. Geneva, 1980.

2 Bravo LL, Ratard RC. Leprosy disabilities in the New Hebrides. Lepr Rev, 1977; 48: 247-60.

${ }^{3}$ Keeler RF, Ryan MA. The incidence of disabilities in leprosy after the commencement of chemotherapy. Lepr Rev, 1980; 51: 149-54.

${ }^{4}$ Price JE. A study of leprosy patients with deformities and implication for the treatment of all leprosy patients. Lepr Rev, 1983; 54: 129-37.

${ }^{5}$ Rao PSS, Karat S, Karat ABA, Furmen MA. Prevalance of deformities and disabilities among leprosy patients in an endemic area. Int J Lepr, 1970; 38: 1-11.

${ }^{6}$ Reddy BN, Bansal RD. An epidemiological study of leprosy disability in a leprosy endemic rural population. Int J Lepr, 1984; 56: 191-99.

7 Smith WCS, Antin US, Patole AR. Disability in leprosy: A relevant measurement of progress in leprosy control. Lepr Rev, 1980; 51: 55-66.

${ }^{8}$ Hasan S. An appraisal of use of the classification of disabilities resulting from leprosy in field work and suggestions for improvement. Lepr India, 1982; 54: 135-42.

9 Kulkarni UP, Kulkarni VN, Jogaikar DG. Classification of disabilities as followed by Poona district leprosy committee. Lepr India, 1984; 56: 269-79.

${ }^{10}$ Bell JA. Deformity and neural status hand screen. The Star, 1984; 44(3): 1-4.

1 Brandsma JW. Basic nerve function assessment in leprosy patients. Lepr Rev, 1981; 52: 161-70.

12 Brandsma, JW. Nerve function testing and evaluation. Part 1, The Star, 1984; 43(4): 2-3.

${ }_{13}$ Brandsma JW. Nerve function testing and evaluation. Part 2, The Star 1984; 44(1): 8-10.

14 Naafs B. Tamru Dagne. Sensory testing: A sensitive method in the follow-up of nerve involvement. Int J Lepr, 1977; 45: 364-68.

15 Watson JM. WHO disability grading. Letter to the editor. Lepr Rev 1985; 56: 172-175. 